\title{
A MULTIFUNCIONALIDADE DO ITEM "CAPAZ" NA FALA GAÚCHA: UMA ABORDAGEM BASEADA NO USO
}

\author{
Alessandra BASSI* \\ Edair Maria GÖRSKI*
}

- RESUMO: Sob uma perspectiva teórica funcionalista que busca identificar padrões de uso linguístico que se originam e se estabelecem nas situações comunicativas, o presente estudo investiga a multifuncionalidade do item linguístico "capaz", numa amostra sincrônica atual de fala de informantes gaúchos, captando uma trajetória de mudança semântico-pragmática (associada a valores de modalidade) e categorial (adjetivo > marcador discursivo) que pode ser interpretada como uma instância de gramaticalização. A partir da análise de contextos dialogais, foram identificados: i) valores no âmbito da modalidade epistêmica (possibilidade, probabilidade, dúvida e certeza), derivados de um significado-fonte (habilidade) associado à modalidade orientada para o agente; e ii) outras expressões de subjetividade como surpresa, ironia, alegria. O controle da frequência permitiu esboçar padrões de uso do item: "capaz" é mais recorrente em contextos de certeza (em respostas negativas e afirmativas) e de dúvida/ surpresa, aparecendo predominantemente como item sintaticamente autônomo, na função de marcador discursivo. Verificou-se que a natureza da informação dada pelo interlocutor (pergunta, opinião, fato/notícia), bem como aspectos prosódicos que envolvem o item são determinantes para a interpretação do significado de "capaz".

- PALAVRAS-CHAVE: Capaz. Marcador discursivo. Contexto dialogal. Modalidade. Padrões de uso.

Queria tanto dar um presente pra prenda Ponta de gado, fazenda, e um montão de coisas mais

Dizer palavras, que sei e penso em segredo E que só em pensar tenho medo por isso não sou capaz [...]. Noel Guarany (1973).

\section{INTRODUÇÃO ${ }^{3}$}

Este trabalho se fundamenta numa perspectiva teórica funcionalista - também denominada mais recentemente como teoria baseada no uso (BYBEE, 2010) -,

* UFSC - Universidade Federal de Santa Catarina. Programa de Pós-Graduação em Linguística. Florianópolis SC - Brasil. 88045-401 - alefof@yahoo.com.br

** UFSC - Universidade Federal de Santa Catarina. Programa de Pós-Graduação em Linguística. Florianópolis SC - Brasil. 88061-220 - edagorski@hotmail.com

3 Agradecemos as valiosas contribuições dos pareceristas anônimos. Quaisquer problemas remanescentes são de nossa responsabilidade. 
a qual prioriza a identificação de padrões linguísticos que se originam e se estabelecem nas situações comunicativas, orientados por motivações semânticopragmáticas. A língua é concebida como um sistema adaptativo complexo em constante mudança e variação, cuja estrutura é maleável e emergente e cujas categorias são gradientes (GIVÓN, 1995; HOPPER, 1987). De acordo com essa abordagem, a modalidade "codifica a atitude do falante em relação à proposição" (GIVÓN, 2001, p. 300) - envolvendo julgamento epistêmico ou deôntico -, e é captada no contexto comunicativo que envolve os participantes da situação de interlocução (falante e ouvinte).

Ancorando-se nesse suporte teórico, o objetivo deste estudo é analisar o funcionamento do item "capaz" em ocorrências captadas na fala espontânea de indivíduos gaúchos, sugerindo que esse item se encontra numa trajetória de mudança semântico-pragmática (associada a valores de modalidade) e categorial (adjetivo > marcador discursivo).

Uma busca em alguns dicionários mostra que a palavra "capaz" é proveniente do latim capax (ãcis) com o sentido de largo, extenso, apto, capaz, passando a assumir, por meio de um processo de transferência metafórica, o sentido de "ser possível de" (BUSARELLO, 2005). O Novo dicionário Aurélio da língua portuguesa (FERREIRA, 1986, p.341) caracteriza o item em pauta como adjetivo masculino e feminino e apresenta as seguintes definições:

[...] que tem capacidade; em condições de fazer ou realizar determinada coisa <um homem capaz de heroísmo>; hábil, inteligente <revelouse um chefe capaz>; que está em condições legais para exercer validamente certos direitos <capaz de tudo, que não hesita diante de qualquer coisas.

O Dicionário Houaiss da língua portuguesa (HOUAISS; VILLAR, 2002, p.787) inclui, entre os sentidos registrados para o item, o seguinte: "que tem competência ou habilidade <ele já é capaz de dirigir>, <vidro capaz de isolar o calor>". Percebemos que são recorrentes nos dicionários menções a sentidos no âmbito da modalidade (capacidade, habilidade). Esses sentidos podem ser observados no dado abaixo, retirado da nossa amostra, ${ }^{1}$ bem como na epígrafe deste trabalho:

(1) C: Nossa! Não sei se vou conseguir dar aula. Só fico pensando nessa doença do meu pai.

M: Vai conseguir dar aula sim. Sei que você é capaz. ${ }^{2}$ (hábil/apto, competente)

\footnotetext{
A amostra analisada é constituída por 52 (cinquenta e dois) contextos em que "capaz" aparece numa situação dialógica (cf. (1) a (4)), extraídos da fala espontânea de 20 (vinte) informantes gaúchos. A constituição dessa amostra será detalhada na seção referente à metodologia.

2 Os códigos no início de cada turno identificam os interlocutores nas situações dialógicas.
} 
Ocorre que na fala cotidiana, notadamente no Rio Grande do Sul, ${ }^{3}$ são encontrados frequentemente usos de "capaz" que não se enquadram nas acepções dicionarizadas. Observe-se:

(2) L: Se chover assim não vai ter a Semana Farroupilha.

M: Capaz que não!

(3) M: Eram duas horas quando você me ligou.

C: Capaz que eram duas horas!?

M: Sim, eram duas horas.

(4) E: Tu sabia que aquele comentarista de futebol do jornal do almoço de Santa Catarina, aquele moreno, é gaúcho?

D: Capaz!!!

Usos desse tipo, entre outros encontrados, parecem não ter sido ainda objeto de uma descrição sistemática, ${ }^{4}$ o que motiva nosso interesse em tratar desse assunto. Não é pretensão deste artigo explorar uma grande quantidade de dados, mas evidenciar, a partir de uma análise qualitativa de cada contexto, a multifuncionalidade desse item e depreender, a partir da frequência das ocorrências, possíveis padrões de uso.

Buscam-se evidências para a hipótese de que o item "capaz" apresenta um comportamento multifuncional, expressando, sincronicamente, i) diferentes significados modais que derivam de um significado-fonte associado a habilidade e se expandem pelo caminho das possibilidades, probabilidades, dúvidas e certezas do falante; e ii) categorias gramaticais distintas (adjetivo > marcador discursivo ${ }^{5}$ ),

3 O uso de "capaz" é tão característico no Rio Grande do Sul que é, por vezes, considerado uma marca linguística identitária do gaúcho.

4 Rocha [2008] (inédito) fez um levantamento de usos de "capaz" em textos escritos: Contos gauchescos, de Simões Lopez Neto, tiras de Radicci publicadas no Jornal Zero Hora e divulgadas no site do mesmo autor, revistas on-line de circulação nacional como Veja, Exame, Nova Escola e Cláudia, encontrando apenas usos dicionarizados como (1) e nenhuma ocorrência que fosse semelhante a (2) - (4). A autora realizou ainda uma busca no banco de dados Varsul-RS (Variação Linguística na Região Sul do Brasil), tendo encontrado um número muito insignificante de ocorrências. Registrou, então, alguns dados de fala, aleatoriamente, apontando valores como espanto, alegria, ironia, negação, possibilidade e dúvida, sem, contudo, desenvolver uma análise sistemática desses usos.

5 Os chamados marcadores discursivos - por serem provenientes de diferentes categorias (advérbios, adjetivos, verbos, conjunções, preposições etc.) e por abrangerem itens que atuam tanto no nível das relações entre o falante e o ouvinte, como no das relações entre o falante e seu texto, e ainda no das relações estabelecidas entre partes do texto - não constituem um paradigma homogêneo, sendo comumente considerados como uma classe funcional (SCHIFFRIN, 1987, 2001; RISSO; SILVA; URBANO, 1996, 2006) em vez de formal. A concepção de língua e de gramática adotada neste trabalho permite considerar os marcadores discursivos como parte da gramática da língua, embora basicamente pragmáticos em função (TRAUGOTT, 1995). Não está no escopo deste trabalho, contudo, discutir o estatuto categorial desses itens - se mais ou menos gramatical -, apesar da relevância dessa questão. 
associadas aos respectivos valores modais. Propomos, por fim, que essa mudança pode ser interpretada como uma instância de gramaticalização.

A seguir, apresentamos o referencial teórico, os procedimentos metodológicos e a análise da multifuncionalidade do item "capaz". O referencial teórico está organizado em duas subseções: uma que trata da concepção de gramática e de mudança por gramaticalização; e outra destinada à modalidade.

\section{SUPORTE TEÓRICO}

\section{Concepção de gramática e de gramaticalização}

Nesta abordagem, opera-se com a noção de gramática baseada no uso. Bybee (2006) propõe que a gramática deve ser concebida como a organização cognitiva de nossa experiência com a língua. Nessa mesma direção, Givón vê a gramática como um organismo maleável que se adapta às necessidades cognitivas e comunicativas dos falantes:

[...] as pressões adaptativas que dão forma à estrutura sincrônica ('idealizada') da língua são exercidas durante a performance on-line. É aí que a língua emerge e muda. É aí que as formas se ajustam constantemente a novas funções e significados estendidos. (GIVÓN, 2002, p. 05).

A gramática envolve um repertório de itens que, usados inicialmente de maneira expressiva, se tornam rotinizados por sua recorrência em certos contextos. Nesse sentido, assume importância significativa o papel da frequência para o estabelecimento e a manutenção de padrões linguísticos; e o aumento da frequência de uso de determinado item em diferentes contextos pode ser indício de difusão linguística e social de mudança ${ }^{6}$ (BYBEE, 2010) - processo lento e gradual em que os itens em jogo vão perdendo algumas propriedades e ganhando outras. Situadas num continuum de mudança, as categorias não são discretas, mas gradientes. Em vista disso, o analista se depara, inevitavelmente, com casos de sobreposição de significados/funções, que se refletem na indefinição do status categorial de certos itens, levando o pesquisador a postular categorias híbridas ou casos fronteiriços, ou ainda ambíguos.

Considerando-se a interação entre aspectos cognitivos e comunicativos/ contextuais, a emergência e a difusão de padrões de uso costumam ser explicadas como um processo de gramaticalização - entendida, neste artigo,

Na abordagem funcionalista, mudança refere-se tanto à emergência da inovação, que se dá na interação entre falante e ouvinte, como à propagação social da inovação (HOPPER; TRAUGOTT, 2003). 
como "[...] mudança pela qual itens lexicais e construções passam, em certos contextos linguísticos, a desempenhar funções gramaticais e, uma vez gramaticalizados, continuam a desenvolver novas funções gramaticais." (HOPPER; TRAUGOTT, 2003, p.18, grifo nosso). Atentamos ainda para a seguinte especificação contextual: "[...] processo pelo qual um item lexical [ou uma construção], impulsionado por certo contexto pragmático e morfossintático, torna-se gramatical." (TRAUGOTT, 1995, p.01, grifo nosso). Os trechos grifados nas definições remetem a dois aspectos importantes neste trabalho: i) as funções gramaticais desenvolvidas pelos itens são novas, não necessariamente mais gramaticais; ${ }^{7}$ ii) o contexto pragmático é tão relevante quanto o contexto morfossintático em que ocorre o item em questão. Vale salientar que o desenvolvimento dos itens se dá em contextos de construções específicas (TRAUGOTT, 2003). A alusão a um componente pragmático na definição de gramaticalização parece compatível com a definição de gramática, nos termos de Traugott (1995), como estruturante de aspectos cognitivos e comunicativos da linguagem, englobando não só fonologia, morfossintaxe e semântica, mas também aspectos pragmáticos inferenciais. ${ }^{8}$

A gramaticalização envolve dois tipos de mudança: mudança semânticopragmática e mudança categorial. A primeira trata de motivações i) cognitivas nível de representação concernente à dimensão lexical/etimológica e à mudança metafórica, que se dá por analogia; e ii) comunicativas - nível de informação e relevância concernente à dimensão discursiva/textual e à mudança metonímica ou associativa, que se dá por implicatura conversacional, ou inferências sugeridas generalizadas, resultando em reinterpretação induzida pelo contexto; nesse caso, significados pragmáticos que emergem no contexto de negociação de sentidos pelos interlocutores são reanalisados como significados semânticos codificados. Pode-se dizer, portanto, que significados pragmáticos inferidos do contexto impulsionam a gramaticalização (TRAUGOTT; KÖNIG, 1991; HEINE; CLAUDI; HÜNNEMEYER, 1991; TRAUGOTT, 2002; HOPPER; TRAUGOTT, 2003).

A mudança categorial, por sua vez, costuma ser descrita mediante duas abordagens de trajetórias: i) uma que considera o percurso léxico > gramática, postulada inicialmente por Meillet (1965); e ii) outra que focaliza o percurso discurso > morfossintaxe, proposta por Givón (1979). Traugott e Heine (1991) sugerem que as duas abordagens podem ser combinadas em iii) item lexical usado no discurso > morfossintaxe. Neste trabalho, embora priorizemos a concepção de mudança como motivada por práticas discursivas e sociais que levam em conta

Estamos nos reportando, aqui, à clássica definição de Kurylowicz (1965 apud HEINE; CLAUDI; HÜNNEMEYER, 1991, p. 3, grifo nosso): "A gramaticalização consiste no aumento do grau de avanço de um morfema de um status lexical para um gramatical ou de um status menos gramatical para um mais gramatical."

8 No original: " .... inferences that arise out of linguistic form." (TRAUGOTT, 1995, p. 05). 
a interação entre falante e ouvinte (TRAUGOTT, 2002), aspectos relacionados à fonte lexical também são contemplados em nossa análise.

Diferentes abordagens de mudança oferecem critérios distintos para identificar fenômenos em gramaticalização. O conjunto inter-relacionado de parâmetros ${ }^{9}$ postulado por Heine e Kuteva (2007), abarcando diferentes níveis da língua em uso, parece-nos adequado para a análise aqui proposta: i) extensão - surgimento de novos significados gramaticais associados a novos contextos (reinterpretação induzida pelo contexto); ii) dessemantização - perda (ou generalização) de significado de conteúdo; iii) decategorização - perda de propriedades morfossintáticas; e iv) erosão - perda de substância fonética. A ordenação desses parâmetros, segundo os autores, reproduz a sequência diacrônica em que eles tipicamente se aplicam a fenômenos em processo de gramaticalização.

A visão de gramática e de gramaticalização à qual nos alinhamos abre espaço para que se incluam em seu escopo os chamados marcadores discursivos (cf. nota 4) - elementos de origem diversa que se caracterizam por sua multifuncionalidade. Consideramos que os marcadores discursivos (daqui em diante MDs) são elementos multifuncionais que "[...] [a]marram o texto não só enquanto estrutura verbal cognitiva, mas também enquanto estrutura de interação interpessoal." (URBANO, 1997, p. 86).

O foco na interação leva-nos novamente a considerar a questão da influência de aspectos pragmáticos na mudança linguística. Segundo Traugott (2008), as inovações são feitas tanto pelos falantes (na produção) como pelos ouvintes (na percepção), sendo em sua maioria não intencionais. A autora coloca relevo no que ela chama de discurso dialogal (dialogual discourse), entendido de duas maneiras: i) como interação ampla falante-ouvinte, em que os participantes negociam significados; e ii) como troca de turno (turn-taking) envolvendo pares adjacentes - uma miniconversação vista como contexto de emergência de certas construções. Citando trabalhos de Detges e Waltereit (2003) e Waltereit (2006) sobre o desenvolvimento do MD italiano guarda! (olha!), analisado em contextos de troca de turno, a autora fomenta a ideia de que esses são contextos pragmáticos inerentemente propícios à mudança linguística, favorecida por implicaturas que emergem nesse tipo de contexto. A referência a esses trabalhos é importante para nós, uma vez que o objeto tomado para análise - o item "capaz" - ocorre sistematicamente em pares adjacentes nas interações verbais.

Tratamos, até aqui, de aspectos mais amplos da abordagem teórica assumida. Como o objeto escolhido para estudo carrega nuances de modalidade, passamos a tratar dessa categoria, ainda como suporte teórico para a análise a ser feita posteriormente.

Esses parâmetros constituem uma ferramenta utilizada para identificar e descrever casos de gramaticalização. 


\section{A modalidade}

Numa perspectiva cognitivo-comunicativa da língua, a modalidade é vinculada ao contexto pragmático que envolve os participantes da situação de interlocução, sendo vista como uma categoria que "codifica a atitude do falante em relação à proposição" (GIVÓN, 2001, p. 300), levando em conta o papel do interlocutor. A atitude do falante corresponde, segundo Givón (2001), a dois tipos de julgamento, ambos admitindo matizes e gradações: i) epistêmico-recobrindo valores de verdade, probabilidade, certeza, crença, evidência; e ii) deôntico ou avaliativo - envolvendo valores de desejo, preferência, intenção, obrigação, habilidade, manipulação/poder. Tanto a modalidade deôntica como a epistêmica, segundo o autor, devem ser vistas na dinâmica do contexto, envolvendo uma negociação comunicativa entre falante e ouvinte.

Já Bybee, Perkins e Pagliuca (1994) consideram três tipos de modalidade, sendo os dois primeiros uma espécie de subdivisão do deôntico descrito acima: i) orientada para o agente - reportando a existência de condições internas e externas atuando sobre um agente com relação à realização da ação expressa no predicado principal (é parte do conteúdo proposicional e recobre valores de obrigação, necessidade, desejo, habilidade, possibilidade raiz $(r o o t) ;{ }^{10}$ ii) orientada para o falante - não reportando a existência de condições sobre o agente, mas permitindo ao falante impor tais condições (relaciona-se a atos de fala manipulativos e inclui comando, pedido, aviso, advertência, recomendação, permissão, aconselhamento); iii) epistêmica indicando que o falante está comprometido com a verdade da proposição (não é parte do conteúdo proposicional e expressa possibilidade, probabilidade, certeza inferida). ${ }^{11}$

Para efeitos da análise proposta neste artigo, interessam-nos a modalidade orientada para o agente e a modalidade epistêmica, nos seguintes termos: a modalidade orientada para o agente expressa condições de um agente em relação à execução de uma ação (referida no predicado principal); as origens da modalidade deôntica podem ser externas ou internas ao agente, expressando ação resultante de obrigação, necessidade, desejo, habilidade ou possibilidade raiz; a modalidade epistêmica expressa o grau de comprometimento do falante com a verdade da proposição enunciada; a origem da modalidade epistêmica é usualmente o falante, que conclui a partir de evidências se a proposição é

10 A possibilidade raiz corresponde a uma generalização da habilidade, reportando a existência de condições internas, físicas ou sociais (possibilidades gerais) para a realização da ação (BYBEE; PERKINS; PAGLIUCA, 1994).

11 Não é consensual, entre os autores que tratam de modalidade, a conceituação e classificação dessa categoria. Como não se trata do foco de nossa discussão, remetemos o leitor interessado nessa questão ao texto de Traugott e Dasher (2005) 
verdadeira ou não. Ambos os tipos de modalidade são vistos na dinâmica do contexto comunicativo. Alguns exemplos: ${ }^{12}$

(5) Marcos pode nadar até a costa sem se cansar. "Ele consegue/é capaz de nadar". condição/força interna (habilidade/capacidade).

(6) Certas coisas podem ser associadas ao cromossoma Y.13 "É possível que isso aconteça". - possibilidades/condições gerais (possibilidade raiz).

(7) Maria pode estar cansada, por isso não veio. "O falante pensa que é possível que ela esteja cansada". - grau baixo de comprometimento (possibilidade epistêmica).

(8) Maria deve estar cansada, pois não dormiu esta noite. "A evidência sugere que Maria está cansada/o falante conclui que ela está cansada". - grau maior de comprometimento (probabilidade).

Do ponto de vista da mudança linguística, Bybee, Perkins e Pagliuca (1994) consideram que os significados modais orientados para o agente (não considerados como modalidade em algumas abordagens) são a origem diacrônica da maioria dos sentidos que qualificam as demais modalidades. Interessamnos, particularmente, os valores modais de habilidade, possibilidade (raiz e epistêmica), probabilidade e certeza.

Ainda segundo os autores, no âmbito da modalidade orientada para o agente, a transição de significados modais, por um processo de generalização gradativa, seria: habilidade mental > habilidade física > qualquer habilidade > possibilidade raiz. A mudança orientada para o agente $>$ epistêmico envolve i) uma mudança de escopo: enquanto o modal orientado para o agente é parte do conteúdo proposicional da oração, servindo para relacionar o agente com o predicado principal, o modal epistêmico é externo ao conteúdo proposicional da oração e tem escopo sobre a proposição inteira; e ii) a convencionalização de implicaturas, de modo que inferências que podem ser feitas do significado de um modal particular, por exemplo, tornam-se parte do significado daquele modal. A trajetória de mudança de significados modais seguiria (no sentido de modalidade orientada para o agente a modalidade epistêmica), portanto, a seguinte direção:

\section{... > possibilidade raiz > possibilidade epistêmica.}

A distinção entre possibilidade raiz e possibilidade epistêmica nem sempre é clara. Coates (1995) propõe o termo "fusão" (merger) para designar os casos em que a mesma forma linguística - em sua análise, o verbo modal may - expressa tanto um valor de raiz quanto um valor epistêmico, sendo que o interlocutor pode processar ambas as informações sem ter de escolher uma delas. Essa noção é útil

12 Os exemplos (5), (7) e (8) foram adaptados por nós.

13 "Certain things can be sex-linked to the Y chromosome" (COATES, 1995, p.57). 
para nossa análise, visto a dificuldade em se distinguir esses valores nos poucos dados disponíveis.

Isso posto, considerando que a possibilidade raiz corresponde a uma generalização da habilidade (cf. nota 10), vamos trabalhar com a seguinte hipótese de trajetória, que é ampliada para abarcar também graus maiores de comprometimento do falante com aquilo que é enunciado, assinalando um continuum deôntico-epistêmico com três graus de modalidade epistêmica - foco principal da análise:

\section{habilidade $>$ possibilidade $>$ probabilidade $>$ certeza.}

Cabe pontuar aqui que os exemplos e a discussão acima evidenciam o funcionamento modal dos auxiliares típicos "poder" e "dever"; mas há também outras formas de modalização epistêmica/deôntica a serem consideradas: expressões adverbiais ("talvez", "provavelmente", "certamente", "de fato" etc.), expressões parentéticas ("acho que", "parece que" etc.), orações constituídas de ser + adjetivo ("é possível", "é certo", "é necessário", "é claro" etc.), entre outras.

Outro aspecto teórico que precisa ser realçado em relação à modalidade diz respeito à redefinição do eixo da modalidade epistêmica proposta por Givón (2001): o autor transpõe a modalidade epistêmica do escopo da proposição, como é tratada tradicionalmente na lógica, para o contexto que envolve uma transação comunicativa entre falante e ouvinte. Assim, a verdade necessária, a verdade factual, a verdade possível e a não verdade (da lógica tradicional) são reinterpretadas, respectivamente, nos seguintes termos: i) pressuposição a proposição é admitida como verdadeira (por definição, por convenção culturalmente partilhada, por ter sido enunciada pelo falante e não contestada pelo ouvinte etc.); ii) asserção realis - a proposição é fortemente asserida como verdadeira (embora o falante disponha de evidência para defender sua forte crença, a contestação pelo ouvinte seria apropriada); iii) asserção irrealis a proposição é fracamente asserida como possível, provável ou incerta (o falante não dispõe de evidências para reforçar a asserção e a contestação pelo ouvinte é prontamente recebida ou esperada); iv) asserção negativa - a proposição é fortemente asserida como falsa, comumente em contradição a crenças explícitas ou assumidas pelo ouvinte.

Merece destaque o fato de que Givón (1995) levanta a possibilidade de uma dupla interpretação quanto à asserção negada: do ponto de vista semântico, a negação da asserção pode ser tida como irrealis por partilhar a propriedade de não realizada (não fato); mas do ponto de vista pragmático, por ser fortemente asserida, se comporta como realis, podendo ser agrupada à pressuposição (fato). Essa última possibilidade de interpretação é interessante à medida que ao 
se considerar a negação da asserção como realis, isso permite que se atribua um grau maior de certeza à atitude do falante frente à proposição, o que terá reflexos em nossa análise, como se verá adiante.

É a partir desse embasamento teórico que desenvolvemos a análise do item "capaz", buscando entender seu funcionamento e captar padrões a partir do uso.

\section{PROCEDIMENTOS METODOLÓGICOS}

A amostra analisada neste artigo corresponde a 52 contextos dialogais que contêm o item "capaz". Os dados foram produzidos na fala espontânea de 20 informantes gaúchos de várias localidades do Rio Grande do Sul, que integram a mesorregião do Noroeste Rio-Grandense. Esses informantes estão assim distribuídos quanto ao gênero, faixa etária e nível de escolaridade: 10 homens (cinco com ensino superior e idade abaixo de 40 anos e cinco com ensino fundamental e idade acima de 40 anos) e 10 mulheres (cinco com ensino superior e idade abaixo de 40 anos e cinco com ensino fundamental e idade acima de 40 anos).

Os dados foram coletados ao longo do ano de 2012 por uma das autoras deste artigo, através de anotações de contextos dialogais produzidos em diferentes situações (inclusive em telefonemas), além de gravações realizadas em ambiente familiar informal, em que há certa intimidade entre os interlocutores, uma vez que é nessas situações que o item "capaz" se mostra mais produtivo.

Para a categorização dos diferentes usos de "capaz" em termos de seus valores ${ }^{14}$ modais (possibilidade, probabilidade, dúvida, certeza) e de outros significados agregados (negação, afirmação, expressão de surpresa), contamos com a colaboração de cinco indivíduos gaúchos pertencentes à mesma mesorregião na qual os dados foram coletados. As ocorrências da amostra, transcritas e previamente analisadas por nós, foram apresentadas a esses sujeitos para que eles apontassem a significação de "capaz" em cada um dos contextos, a partir de uma lista de possibilidades previamente elaborada por nós, mas deixada em aberto para eventual complementação. A ideia era validar nossa análise mediante a aplicação desse teste de percepção.

Os dados, embora em número relativamente reduzido, foram posteriormente quantificados para que pudéssemos averiguar a frequência de ocorrências em cada função identificada.

14 Neste trabalho, não fazemos distinção no uso dos termos "valor" e "significado"; também utilizamos de forma alternativa os termos "função" e "significação". Esses termos perpassam a análise da multifuncionalidade do item "capaz", no que concerne a aspectos de natureza semântico-pragmática. 


\section{A MULTIFUNCIONALIDADE DO ITEM “CAPAZ”}

Todas as ocorrências de nossa amostra aparecem em contexto dialogal. O falante que produz o "capaz" está sempre interagindo com um interlocutor, seja colocando em dúvida uma afirmação ou se contrapondo a ela, seja respondendo a uma pergunta. Nesse sentido, é preciso analisar o item em seu funcionamento na troca de turno de um par adjacente.

No decorrer da análise notamos que "capaz", além de atuar no campo da modalidade, carregando especialmente diferentes graus de certeza, também agrega outros significados como negação, expressão de surpresa associada a dúvida, alegria, ironia - esses últimos fortemente marcados por traços prosódicos. Assim, procedemos à análise considerando três parâmetros, os dois primeiros de natureza semântico-pragmática e o terceiro de natureza morfossintática, contemplando, respectivamente: a modalidade, significados agregados e a mudança categorial do item.

Dos 52 contextos analisados, dois correspondem à modalidade deôntica e 50 à modalidade epistêmica, que é o foco principal da discussão. As ocorrências (1) e (9) são consideradas apenas para evidenciar que o uso desse item como adjetivo expressando capacidade/habilidade coexiste com outros usos, como em (2) a (4) e em (10).

(9) E:Você tem que escolher muito bem a segunda graduação que pretende fazer. L: Pois é, mas eu gostaria de ter ao meu lado uma pessoa que fosse capaz de me acompanhar durante o curso, uma pessoa em quem eu pudesse confiar e fazer os trabalhos junto.

(10) V:Acho que vou ter que passar mais uns dois meses em Porto Alegre. Tenho que fazer mais um monte de exames médicos.

E: Capaz, vó!

Em (9), o adjetivo "capaz" é parte do conteúdo proposicional e remete à existência de condições internas do agente ("uma pessoa") para executar a ação expressa no predicado principal ("acompanhar durante o curso"). Trata-se de um caso de modalidade orientada para o agente. Em (10), "capaz" não faz parte do conteúdo proposicional e expressa a atitude do falante $\mathrm{E}$, não diante do que ele próprio vai enunciar, mas em relação ao enunciado proferido pelo interlocutor V. ${ }^{15}$ Notamos, em (10), um traço de modalidade epistêmica: "capaz" é usado com sentido de "é mesmo?", "é verdade?". Além disso, expressa espanto, num misto de surpresa e dúvida. Nesse caso, funciona como marcador discursivo com

15 No decorrer da análise, para facilitar a identificação do participante, nomeamos o informante que produz o dado "capaz" como "falante" e o seu par na situação dialógica como "interlocutor". 
características de interjeição. Essa análise de (10) evidencia, grosso modo, a aplicação dos três parâmetros propostos mais acima.

\section{Expressão de modalidade e outros significados agregados}

Nesta subseção, focalizamos, num primeiro momento, o funcionamento de "capaz" no plano da modalidade e, num segundo momento, refinamos a análise levando em conta outros significados que eventualmente se sobrepõem aos valores modais.

Em relação à modalidade, deixando de lado a habilidade (valor modal de origem - ser capaz de, típico do adjetivo/predicativo), consideramos os valores: possibilidade, probabilidade e certeza. A análise será conduzida de acordo com esse gradiente de modalidade presente nos dados.

Observemos, inicialmente, as seguintes ocorrências:

(11) V: Eu não estou muito bem de saúde.

A: Capaz que isso tudo que você sente é algum problema no sangue.

(12) S: Será que se eu deixar o celular aqui para reservar a mesa e for ao banheiro, alguém pode passar e levar o meu celular?

D: É bem capaz...

Nesses dois contextos, "capaz" está atuando na dimensão da modalidade epistêmica de baixa certeza. Em (11), o falante A, a partir do enunciado de V a respeito de seu próprio estado de saúde, julga ser possível que o interlocutor esteja com algum problema no sangue. Em (12), pistas contextuais sugerem que há um comprometimento um pouco maior do falante com o conteúdo da proposição que ele enuncia: naquela situação há probabilidade de que o celular seja roubado.

Em ambas as ocorrências, o escopo de atuação de "capaz" é o conteúdo proposicional que está articulado sintaticamente ao item, no próprio enunciado do falante. Note-se que em (12) a interrupção sinaliza a não retomada da informação expressa na pergunta do interlocutor: "É bem capaz [que levem seu celular]". Em nenhum desses casos o falante se contrapõe a seu interlocutor; ele dá continuidade ao fluxo discursivo opinando (11) e respondendo afirmativamente (12). Temos, nesses dados, "capaz" funcionando como expressão modal de possibilidade > probabilidade, num gradiente de comprometimento do falante com a verdade da proposição enunciada por ele.

Examinemos o próximo conjunto de dados: 
(13) N: E o Flávio, como é que está nas pesquisas políticas?

B: O Flávio tá bem, ele está em terceiro lugar como vereador.

N: Capaz que ele está em terceiro lugar!?

B: Sim.

$\mathrm{N}$ : O pessoal estava comentando que ele estava indo bem e eu não acreditei, então é verdade.

(14) Na: Sabia que a minha filha disse que essas cores que você escolheu para fazer os tapetes vão ficar bem bonitas juntas?

Ni: Capaz que ela disse isso! Que legal!

(15) L: Tu viu quem saiu do Big Brother Brasil?

E: O Ivan saiu.

L: Capaz!!!

E: Sim, saiu com 48\%.

L: Nossa! Eu achei que as pessoas gostavam do Ivan.

(16) C: Essa carne que você assou hoje ficou dura.

M: Capaz!! Eu fiz com tanto cuidado!

Diferentemente dos exemplos (11) e (12), neste grupo o escopo de "capaz" não recai sobre a proposição enunciada na sequência pelo falante, mas sobre o conteúdo informado anteriormente pelo interlocutor. O falante não adere, de imediato, à informação que lhe foi apresentada. Num primeiro momento, ele reage colocando em dúvida o que foi afirmado, ao dizer, em tom enfático, "capaz!". Este item, nos contextos (13) a (16), tem o valor de "não acredito nisso" ou "é verdade?" "é mesmo?". É como se o falante pedisse confirmação daquilo que foi informado. É o que se verifica em (13), quando N põe em xeque a informação de que Flávio está em terceiro lugar nas pesquisas para vereador: "Capaz que ele está em terceiro lugar!?", e o interlocutor B confirma: "Sim".

Em (14) e (15), a informação dada pelo interlocutor é codificada como se fosse pressuposta, pois aparece atrelada a verbo de cognição/percepção que checa o conhecimento do falante: "Sabia que...?/Tu viu quem...?". Observa-se, em (14), que o falante faz inicialmente uma objeção: "Capaz que ela disse isso!". Mas imediatamente mostra que aceitou a informação ao avaliar: "Que legal!", sem esperar que o interlocutor confirme. Nota-se que existem diferentes graus de adesão do falante: em (15), a aceitação da informação de que Ivan foi quem saiu do BBB fica explicitada apenas após a confirmação dada pelo interlocutor: "Sim, saiu com 48\%". Já em (16), não se tem certeza de que M concorde com a afirmação de C de que a carne ficou dura, quando replica: "Capaz!! Eu fiz com tanto cuidado!".

Do ponto de vista da modalidade, essas ocorrências podem ser caracterizadas como de adesão não imediata do falante ao conteúdo proposicional, via 
de regra factual, apresentado pelo interlocutor. O falante coloca em dúvida o conteúdo da informação antes de aceitá-lo. Nesse sentido, num gradiente de modalidade, elas provavelmente se situariam entre a possibilidade/probabilidade e a certeza.

Um terceiro bloco de dados é apresentado a seguir:

(17) L: E aí, gostaram do presente de casamento?

C: Mas capaz que não! O hotel era maravilhoso.

(18) M: Nós vamos lá na mãe colher jabuticaba.

C: E demora para colher jabuticaba?

M: Capaz, é bem rápido!

(19) E: Mas você fica aí reclamando do teu salário, por que você não faz uma especialização?

P: Capaz! Eu já fiz uma graduação e para ensinar a garotada com graduação chega.

(20) C: Então eu te encontro na Universidade.

M: Mas bem capaz!!! Para que eu vou voltar até lá? Vamos marcar outro lugar.

O que particulariza esse bloco é o alto grau de certeza expresso pelo item "capaz" em cada um dos contextos. Em (17), a resposta com a construção "capaz que não" equivale a "claro que sim", revelando a adesão imediata do falante, que responde afirmativa e convictamente à indagação do interlocutor, inclusive justificando sua pronta resposta. Parafraseando: "claro que gostamos do presente, pois o hotel era maravilhoso".

Já em (18) a (20), "capaz" equivale a "não". Novamente o falante demonstra não ter dúvidas em relação ao que lhe é perguntado ou proposto e a resposta, nos três casos, é imediata. Pode-se notar que há um crescendo no grau de convicção com que o falante se coloca: no primeiro dado, "Capaz" poderia ser substituído simplesmente por "Não"; no segundo, a negação é mais enfática: "Não!"; no último, o item é intensificado e "Mas bem capaz!!!" equivale a algo do tipo "De jeito nenhum!!!".

O ponto de contraste entre as ocorrências desse terceiro bloco é que, enquanto em (17) o falante entra em acordo com o interlocutor e responde afirmativamente, em (18) a (20) a resposta é negativa. Em todos os casos, porém, o grau de certeza em relação ao que é enunciado é alto. Vale mencionar aqui a observação de Givón (1995), referida na seção teórica, a respeito da asserção negada no eixo da modalidade epistêmica: embora possa ser vista como irrealis por ser não realizada, do ponto de vista pragmático se comporta como realis por ser fortemente asserida. 
Essa interpretação pode ser transposta para o contexto dialogal de nossos dados. O falante tem certeza daquilo que está declarando ao seu interlocutor, seja afirmando ou negando uma asserção.

A distribuição dos dados analisados quanto à modalidade pode ser conferida na Tabela 1.

Tabela 1 - Distribuição de "capaz" quanto a valores modais

\begin{tabular}{ccc}
\hline Modalidade & $\mathbf{N}^{\circ}$ de ocorrências & Percentual \\
\hline Certeza & 26 & $52 \%$ \\
Dúvida/certeza & 18 & $36 \%$ \\
Probabilidade & 04 & $08 \%$ \\
Possibilidade & 02 & $04 \%$ \\
\hline Total & 50 & $100 \%$ \\
\hline
\end{tabular}

Fonte: Elaboração própria.

Podemos definir, a partir desses resultados, dois padrões principais de uso de "capaz" quanto à modalidade: mais da metade das ocorrências examinadas veicula atitude de certeza do falante diante do que é proposto pelo interlocutor; e mais de um terço das ocorrências se caracterizam por apresentar a propriedade de o falante primeiramente pôr em xeque o conteúdo enunciado pelo interlocutor para então aderir a ele. Esses são os campos de atuação preferencial de "capaz" na amostra analisada, ambos colocando fortemente em cena o papel do interlocutor.

Em resumo: os dados examinados transitam em contextos de modalidade epistêmica, distribuindo-se no gradiente possibilidade $>$ probabilidade $>$ certeza e apresentando configurações morfossintáticas e discursivas que caracterizam esses usos modais. Ao expressar possibilidade e probabilidade, o escopo de atuação de "capaz" é o conteúdo proposicional que se vincula ao item no enunciado do falante. Mais ou menos a meio caminho entre esses dois valores e a certeza, situa-se um conjunto de ocorrências que se particularizam por retardarem, mesmo que sutilmente, a adesão imediata do falante ao que é dito pelo interlocutor; são contextos em que "capaz" exprime certa dúvida e toma como escopo o conteúdo proposicional enunciado pelo interlocutor. Por fim, expressando alto grau de certeza, há ocorrências que se caracterizam por revelar um posicionamento firme do falante em relação ao que lhe é proposto pelo interlocutor, seja dando o falante uma resposta afirmativa ou negativa. Os dois últimos tipos de contexto correspondem às principais tendências de uso de "capaz" no campo da modalidade. 
Passemos, agora, ao segundo momento da análise que leva em conta o parâmetro semântico-pragmático, observando o que chamamos de significados agregados. Já apontamos que, além de expressar diferentes graus de modalidade epistêmica, o item "capaz" carrega também outras funções/significações, a depender do contexto. Com o intuito de refinar a descrição do funcionamento desse item, procedemos a um exame mais minucioso de cada ocorrência, procurando captar esses significados agregados. Três valores adicionais foram identificados: negação, afirmação e expressão de surpresa, cada um deles apresentando diferentes matizes, como veremos a seguir.

Os valores de negação e afirmação se sobrepõem ao valor modal de certeza. Dos $52 \%$ de contextos de certeza (cf. Tabela 1), 38\% são de negação e 14\% de afirmação. O exame dos dados mostrou que o valor de negação funciona de formas distintas, a depender dos contextos de enunciação. Diferentes usos de "capaz" com valor de negação podem ser conferidos no conjunto de dados abaixo.

(21) L: Pai, aqui você tem que dobrar à direita.

N: Mas capaz! Aqui eu tenho que ir reto, não tem que dobrar à direita nada.

(22) L: Não presta comer essa pele do frango.

V: Mas capaz! Eu sempre comi e nunca me fez mal.

(23) N: Hoje eu fui na loja trocar o vestido por uma calça.

E: E aí?

N: Sim, eu queria trocar o vestido por uma calça branca número 40. Capaz que serviu, era tão pequenininha.

(24) F: A gente poderia, neste feriado, ir pescar lá no Guaíba. O que tu acha da minha ideia?

R: Ah tá, capaz que eu vou pescar contigo! Nem falar.

Em (21), "Mas capaz!" corresponde a "Não!". O falante N recusa a indicação dada pelo filho para que ele dobrasse à direita, e reforça enfaticamente sua decisão complementando a resposta: "Aqui eu tenho que ir reto, não tem que dobrar à direita nada". Em (22), "Mas capaz!" equivale a "Não é verdade que não presta comer essa pele do frango' - interpretação ratificada na sequência do enunciado: "Eu sempre comi e nunca me fez mal". O falante V não só refuta a avaliação negativa feita pelo interlocutor $L$ a respeito de $X$, como oferece uma evidência factual para justificar sua discordância. Em ambos os casos, o valor de negação de "capaz" incide sobre o conteúdo da fala do interlocutor, em (21) sobre um enunciado imperativo, e em (22) sobre toda a asserção negada pelo interlocutor. 
Em (23), o escopo da negação por meio de "capaz" recai sobre uma declaração afirmativa feita pela própria falante: "Sim, eu queria trocar o vestido por uma calça branca número 40". Ela tinha a expectativa de que a calça lhe serviria, mas sua expectativa não foi confirmada, pois a calça era muito pequena. Nesse caso, "Capaz que serviu" tem valor de "claro que não serviu". Há um matiz adicional de contraexpectativa nesse caso. Diferentemente dos dois contextos anteriores, neste a negação incide sobre a própria declaração da falante $\mathrm{N}$.

Observe-se que não é a presença ou ausência de "mas" no enunciado, como pode parecer à primeira vista, que afeta o significado que foi depreendido de cada contexto. Em (21) e (22), "mas" aparece explícito diante de "capaz", ao passo que em (23) e (24) esse vocábulo não aparece. O que se nota é que se "mas" estivesse presente nesses dois últimos contextos não afetaria a interpretação acima atribuída; da mesma maneira, poderia ser omitido nos dois primeiros contextos sem prejuízo à significação já descrita. Trata-se de um recurso de ênfase nesses contextos, bastante recorrente na amostra analisada.

Em (24), o interlocutor F propõe que R participe de uma pescaria com ele: "A gente poderia, neste feriado, ir pescar lá no Guaíba", e pergunta: "O que tu acha da minha ideia?". A resposta de R "Ah tá, capaz que eu vou pescar contigo!" não só é negativa, como carregada de ironia, facilmente percebida pela entonação (representada de forma grosseira como "capázzz").

Cabe aqui um comentário adicional: como os dados foram coletados por uma das autoras, é relativamente fácil reconhecer, em cada contexto analisado, o tipo de curva prosódica que acompanhava o item. No entanto, deixamos de representar graficamente os padrões prosódicos, uma vez que não utilizamos nenhum recurso técnico ${ }^{16}$ para analisar a curva prosódica das ocorrências de "capaz". Não obstante, acreditamos que essa lacuna não se constitui num empecilho para a análise proposta neste trabalho.

O conjunto de dados a seguir mostra contextos em que "capaz" atua com valor de afirmação. Como um mesmo item pode expressar significados opostos (negação e afirmação)? É claro que a depreensão dos diferentes valores do item é sempre dependente de contexto. Examinemos, pois, os contextos das ocorrências a seguir.

(25) C: Eu acho as aulas da estagiária bem boas. Tá certo que às vezes ela não vem trabalhar, mas as aulas dela são boas. Os alunos gostam dela.

P: Mas capaz que eles não iam gostar dela! Ela deixa eles conversarem durante a aula toda dela.

16 O software livre PRAAT, desenvolvido por Boersma e Weenik (2009) para análise e síntese da fala, poderia ser utilizado para esse fim. 
(26) L: Se chover assim não vai ter a Semana Farroupilha. M: Capaz que não! [dado já apresentado como (2)]

(27) N: Mas e tu vai no cinema sábado?

A: Bem capaz que não! Já estou melhor de saúde agora.

Como já apontamos anteriormente, ao discutirmos o valor modal de certeza, é a construção "capaz que não" que equivale ao significado de "claro que sim". Trata-se de uma negação da negação, resultando num valor positivo. No dado (25), o interlocutor C conclui sua fala sobre a estagiária afirmando que os alunos gostam dela. O falante P retruca repetindo parte dessa informação: "Mas capaz que eles não iam gostar dela!", e complementa com uma justificativa para essa resposta: "Ela deixa eles conversarem durante a aula toda dela".

No exemplo (26), o interlocutor L apresenta uma assertiva condicional com negação: "Se chover assim não vai ter a Semana Farroupilha", ao que o falante A prontamente redargui: "Capaz que não!". Ao negar o não fato que L tinha como certo, ou seja, ao negar uma negação, A produz um enunciado com valor afirmativo, interpretado como "Claro que sim, vai ter a Semana Farroupilha com chuva ou sem chuva".

Em (27), o interlocutor N faz uma pergunta: "Mas e tu vai no cinema sábado?", à qual o falante A responde: "Bem capaz que não!". A interpretação dessa resposta como afirmativa é corroborada pela explicação que segue: "Já estou melhor de saúde agora". Observe-se que, se não houvesse esse complemento na resposta e se não se levasse em conta a entonação do segmento que contém "capaz", seria possível entender que A teria dito "É bem capaz que não vá", dando, portanto, uma resposta negativa ao interlocutor. Novamente fica evidente o papel importante dos fatores prosódicos para a adequada interpretação do item.

A expressão de surpresa, por sua vez, se sobrepõe aos dados de dúvida/ certeza (Tabela 1). Nesses contextos, o item aparece normalmente isolado, com independência sintática e acentuada força prosódica, comportando-se como um marcador discursivo que exprime diferentes reações subjetivas do falante. $\mathrm{O}$ valor do uso de "capaz" depende fundamentalmente do contexto e da entoação. Vejamos o conjunto de dados a seguir.

(28) E: Mãe, quanto deu o acerto do pai?

$\mathrm{N}$ : Deu 500 reais.

E: Capaz!? Não era para dar mais do que isso?

N: Sim, claro que era para dar mais. 
(29) B: Você sabia que tem uma pessoa que eu conheço, que foi fazer doutorado sanduíche na França e ficou depressiva?

L: Capaz!!! Nossa! Nunca vi alguém ficar depressivo em Paris, que coisa.

(30) E: Tu sabe que duas pessoas de Erechim morreram naquela tragédia em Santa Maria?

C: Capaz! Tu conhecia algum deles?

E: Não. Só sei que era uma guria e um rapaz.

$\mathrm{E}$ : A minha mãe conhece o pai do rapaz que morreu.

C: Nossa! Que acidente esse.

(31) E: Mãe, sabia que todos os quatro amigos do meu marido tiveram filhos, todos meninos.

N: Capaz! Que legal! Parece que sempre nascem mais meninas, mas neste caso foi o contrário.

Nas quatro ocorrências acima, a resposta "Capaz!" parece ser forma reduzida da construção "Capaz que x!", ficando subentendida a informação " $x$ " dada pelo primeiro interlocutor. No exemplo (28), a assertiva proferida por $\mathrm{N}$, "[O acerto] deu 500 reais", é questionada por E: "Capaz!? Não era para dar mais do que isso?". A surpresa do falante é mesclada com dúvida, como fica evidenciado na interrogação que sequencia sua fala, exteriorizando sua discordância, pois ele acredita na possibilidade de engano em relação ao acerto, o que é sustentado pelo comentário final da mãe "Sim, claro que era para dar mais". Em (30) também se observa um misto de surpresa e dúvida diante da declaração de B acerca da pessoa que ficou depressiva em Paris. A resposta de L, "Capaz!!! Nossa! Nunca vi alguém ficar depressivo em Paris...", traz, além de duas expressões de espanto, a informação adicional que justifica sua dúvida.

Em (30), o interlocutor E faz uma pergunta a $\mathrm{C}$ a respeito de uma tragédia amplamente divulgada que ocorrera em Santa Maria, indagando se C sabia que duas pessoas de Erechim tinham morrido naquele episódio. A resposta "Capaz!" revela surpresa de $\mathrm{C}$ diante da notícia, o qual aceita rapidamente a declaração do interlocutor, já que continua o diálogo (como se não houvesse dúvida sobre o fato declarado), perguntando: "Tu conhecia algum deles?". Por fim, em (31), N reage com surpresa e alegria à notícia de que os amigos do marido da interlocutora tiveram filhos homens. A nuance de alegria é depreendida, além da entonação de "capaz" ("capaaaaz!!!"), também da situação reportada e do comentário avaliativo "Que legal!".

Conforme vimos enfatizando, o contorno prosódico e o contexto são fatores decisivos para identificar as funções (e suas nuances) desempenhadas pelo item "capaz" na amostra analisada. Esses fatores, especialmente o primeiro, ganham 
especial relevo no conjunto de ocorrências de "capaz" caracterizado como expressão de surpresa.

Por fim, não foram encontrados outros significados agregados aos valores modais de probabilidade e possibilidade, associados à relativamente baixa certeza do falante a respeito do conteúdo da proposição que ele próprio enuncia. Esses foram os contextos que se mostraram menos produtivos na amostra analisada. Nas ocorrências a seguir, as construções "é bem capaz que eles venham" e "é bem capaz que eu vá" podem ser parafraseadas como "talvez eles venham" e "talvez eu vá".

(32) V: E os teus parentes lá de São Bento do Sul, não vieram?

N: Não, é bem capaz que eles venham para o próximo feriado.

(33) N: Por que tu não vai no aniversário do Sandro?

V: É bem capaz que eu vá.

Embora o "talvez" caiba em ambos os enunciados encabeçados por "é bem capaz", nota-se, pelo contexto, que em (32) a vinda é possível e em (33) a ida é provável, num gradiente de modalidade epistêmica.

\section{Mudança categorial de "capaz"}

Retomamos alguns dados já analisados, entre outros que apresentamos a seguir, buscando evidenciar as alterações de natureza morfossintática notadamente reduções - que caracterizam os diferentes usos de "capaz" vistos até aqui.

(34) C: Nossa! Não sei se vou conseguir dar aula. Só fico pensando nessa doença do meu pai.

M:Vai conseguir dar aula sim. Sei que você é capaz. [dado já apresentado como (1)]

Este é um contexto em que "capaz" funciona como adjetivo/predicativo significando "hábil" - campo da modalidade orientada para o agente com valor de habilidade/capacidade. Contextos desse tipo, como já dito, são considerados na análise apenas para efeito de comparação com os contextos em que "capaz" expressa modalidade epistêmica.

(35) N: E tu não vai vir para cá para dar uma força para a tua tia, por causa do teu primo que foi internado?

E: É bem capaz que eu vá para a Páscoa, mas tenho que ver umas coisas ainda... 
(36) $\mathrm{N}$ e A chegam na casa de $\mathrm{V}$ depois de um longo passeio. Então, $\mathrm{V}$ diz:

V: Capaz que vocês querem comer cuca ou bolacha...

N: Não queremos comer nada. Obrigada.

Nas ocorrências (35) e (36), "capaz' ainda funciona como adjetivo, porém significando "possível" ou "provável" e encabeçando orações subordinadas subjetivas introduzidas por "que" - campo da modalidade epistêmica com valor de possibilidade/probabilidade. Note-se que em (36) o verbo "ser" foi omitido antes de "capaz".

(37) C: Será que fazendo o tratamento com esse médico o meu pai ficará bem de saúde? $\mathrm{J}$ : Bem capaz que ele não vai atender bem o teu pai.

(38) L: E aí, gostaram do presente de casamento?

C: Mas capaz que não! O hotel era maravilhoso. [dado já apresentado como (17)]

Em (37) e (38) "capaz", sem o verbo "ser" no início, ainda aparece combinado a "que", porém o estatuto sintático da oração introduzida por "que" não é tão claro como em (35) e (36), embora se possa ainda perceber vestígios de oração subjetiva. Em (37) e (38) temos a construção "capaz que não" usada com significado de "é claro que sim" - campo da modalidade epistêmica com valor de certeza.

(39) M: Eram duas horas quando você me ligou.

C: Capaz que eram duas horas!?

M: Sim, eram duas horas. [dado já apresentado como (3)]

(40) E: Tu sabia que aquele comentarista de futebol do jornal do almoço de Santa Catarina, aquele moreno, é gaúcho?

D: Capaz!!! [dado já apresentado como (4)]

Em (39) e (40), "capaz" - expressando surpresa - apresenta comportamento sintático distinto: enquanto no primeiro caso é seguido de oração introduzida por "que", retendo ainda alguma característica de oração subjetiva, no segundo aparece isolado, funcionando claramente como marcador discursivo. "Capaz", nesses casos, apresenta o sentido de "é verdade?" - campo da modalidade epistêmica com valor de dúvida. Nessas ocorrências, se em vez de "capaz" tivéssemos "é verdade", a oração subordinada seria sem dúvida subjetiva. Observe-se que no uso de "capaz" como MD omite-se a oração subsequente: "Capaz [que aquele moço é gaúcho]!".

(41) Gi: E tu cara, quando que vai casar? Eu já casei.

Gui: Casar, eu? Capaz!!! Melhor ficar solteiro. Não tenho nem namorada. 
Por fim, em (41) "capaz" aparece completamente autônomo, atuando como verdadeira interjeição.

Como podemos perceber na descrição acima, a mudança categorial de "capaz" de adjetivo para interjeição é gradual e acompanhada de mudanças semânticopragmáticas no campo da modalidade. Os valores funcionais que identificamos na amostra distribuem-se de modo diferenciado em relação às construções "(é) capaz que [...]" e "capaz!", conforme mostra a Tabela 2.

Tabela 2 - Distribuição de "(é) capaz que [...]"

e "capaz!" quanto aos valores funcionais

\begin{tabular}{c|c|c|c|c|c}
\hline & \multicolumn{2}{|c|}{ (É) capaz que [...] } & \multicolumn{2}{c|}{ Capaz! } & \\
\hline $\begin{array}{c}\text { Valores } \\
\text { funcionais }\end{array}$ & $\begin{array}{c}\mathbf{N}^{\circ} \text { de } \\
\text { ocorrências }\end{array}$ & Percentual & $\begin{array}{c}\mathbf{N}^{\circ} \text { de } \\
\text { ocorrências }\end{array}$ & Percentual & Total \\
\hline Negação & 05 & $26 \%$ & 14 & $74 \%$ & 19 \\
Afirmação & 06 & $86 \%$ & 01 & $24 \%$ & 07 \\
Valor de surpresa & 03 & $17 \%$ & 15 & $83 \%$ & 18 \\
Valor de "talvez" & 05 & $83 \%$ & 01 & $17 \%$ & 06 \\
\hline Total & 19 & $38 \%$ & 31 & $62 \%$ & $50 / 100 \%$ \\
\hline
\end{tabular}

Fonte: Elaboração própria.

A forma reduzida de "capaz!", como item sintaticamente autônomo, é largamente mais utilizada (62\%) do que a construção sintaticamente complexa (38\%). Enquanto a construção "(é) capaz que [...]" predomina nos contextos de afirmação (na forma de "capaz que não") e com valor de "talvez" (com significado de "é possível, é provável"), o item "capaz!" prevalece nos contextos com valor de surpresa/dúvida e negação.

\section{Discussão}

Nas subseções precedentes conduzimos nossa análise ancorada em uma abordagem funcionalista da gramática baseada no uso, considerando, para uma adequada interpretação de "capaz" em cada contexto examinado, aspectos pragmáticos que envolvem as situações dialógicas, o papel dos interlocutores, do conhecimento compartilhado e das inferências, bem como a atuação de elementos suprassegmentais, uma vez que a curva entoacional atribui ao item "capaz" diferentes matizes que se agregam a um gradiente de modalidade. Gostaríamos agora de retomar e colocar em discussão alguns 
pontos, a partir da seguinte indagação: Como os interlocutores distinguem e interpretam adequadamente cada ocorrência de "capaz" sem acarretar prejuízo à comunicação?

Um aspecto importante a ser considerado é, a nosso ver, que os diferentes usos não ocorrem aleatoriamente. Eles são motivados por práticas discursivas que levam em conta a interação entre falante e ouvinte (TRAUGOTT, 2002) e se dão num processo de expansão gradativa que envolve extensão de uso a novos contextos, dessemantização e decategorização (HEINE; KUTEVA, 2007), bem como redução de contexto morfossintático - o que não implica que os empregos originais do item sejam substituídos, uma vez que os diferentes usos podem coexistir. Nesse processo de mudança, em que supostamente usos puramente expressivos passam a se tornar rotinizados, o papel da frequência é relevante, permitindo a identificação de padrões funcionais, como vimos na análise realizada nas subseções anteriores.

Assim, com base na literatura sobre mudança semântico-pragmática e categorial, especialmente voltada à modalidade, a análise de nossa amostra levanos a sugerir o percurso de mudança para o item "capaz" delineado a seguir.

Figura 1 - Hipótese de trajetória de mudança semânticopragmática e categorial do item "capaz"17

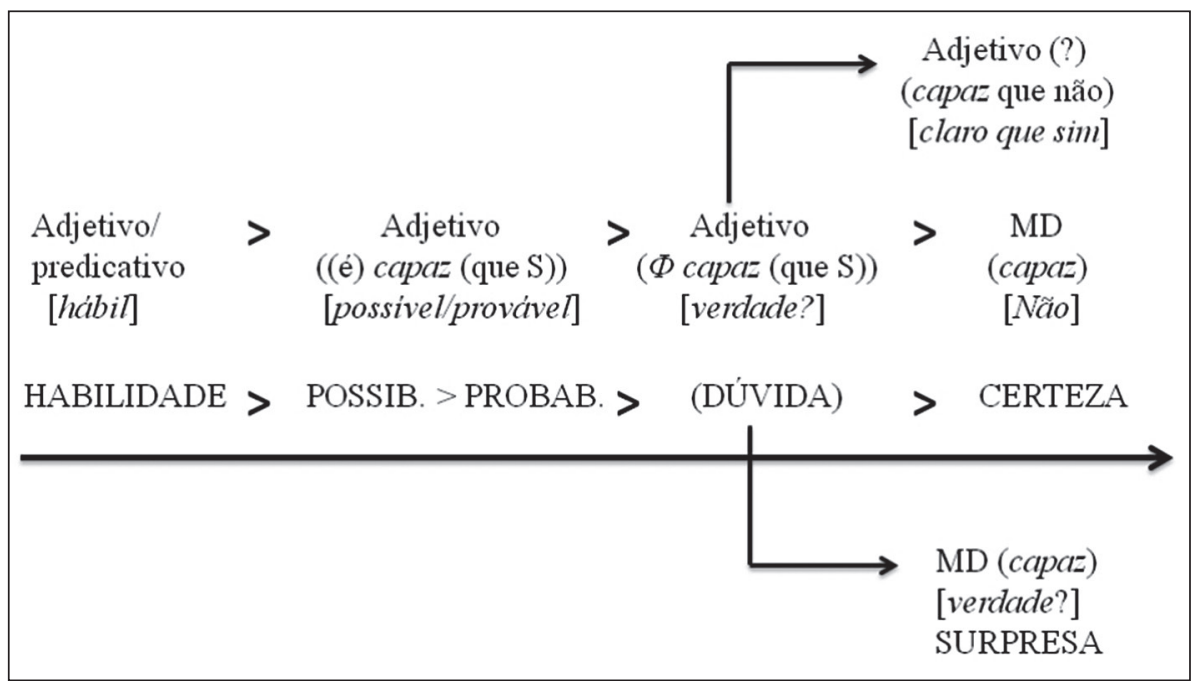

Fonte: Elaboração própria.

17 Convém salientar que a categorização associada a cada etapa representada na figura não é categórica, mas aponta para tendências, conforme mostrado nas tabelas. 
A Figura 1 permite visualizar um continuum de mudança de significados associada à mudança categorial do item "capaz". Acreditamos que os dados analisados, embora em número relativamente reduzido, sustentam essa hipótese de trajetória, conforme evidenciamos a seguir. Observemos as ocorrências em blocos, conforme a direção esboçada no diagrama.

(42) C: Nossa! Não sei se vou conseguir dar aula. Só fico pensando nessa doença do meu pai.

M: Vai conseguir dar aula sim. Sei que você é capaz. [dado apresentado como (1) e (34)]

(43) V: Eu não estou muito bem de saúde.

A: Capaz que isso tudo que você sente é algum problema no sangue. [dado apresentado como (11)]

(44) S: Será que se eu deixar o celular aqui para reservar a mesa e for ao banheiro, alguém pode passar e levar o meu celular?

D: É bem capaz... [dado apresentado como (12)]

Nesses contextos, "capaz" funciona como adjetivo: em (42) como predicativo significando "hábil" e em (43) e (44) como constituinte de oração matriz que encabeça uma subjetiva - em (43) com o verbo "ser" omitido e em (44) com a oração subjetiva elidida ("que levem") -, significando "possível" e "provável", respectivamente.

A posição na figura correspondente ao contexto de dúvida também está associada à categoria adjetivo. Representamos essa instância entre parênteses, uma vez que destoa do clássico continuum de modalidade que deriva o valor de certeza do valor de probabilidade. Optamos por inserir a dúvida na linha principal da trajetória uma vez que apresenta traços de modalidade epistêmica associados à crença do falante. Trata-se de um contexto peculiar que parece funcionar como gatilho para diferentes funções: na sequência do gradiente linear a dúvida dá lugar à certeza; tomando outra direção, estende-se para a surpresa. Além disso, situamos paralelamente o adjetivo (?), também do campo da certeza, significando "claro que sim", dada a especificidade desse contexto. Observemos os dados.

(45) N: E o Flávio, como é que está nas pesquisas políticas?

B: O Flávio tá bem, ele está em terceiro lugar como vereador.

$\mathrm{N}$ : Capaz que ele está em terceiro lugar!?

B: Sim.

$\mathrm{N}$ : O pessoal estava comentando que ele estava indo bem e eu não acreditei, então é verdade. [dado apresentado como (13)] 
(46) N: Mas e tu vai no cinema sábado?

A: Bem capaz que não! Já estou melhor de saúde agora. [dado apresentado como (27)]

(47) Gi: E tu cara, quando que vai casar? Eu já casei.

Gui: Casar, eu? Capaz!!! Melhor ficar solteiro. Não tenho nem namorada. [dado apresentado como (41)]

Do ponto de vista categorial, enquanto em (45) "capaz" mantém características de adjetivo em oração matriz ("(é) capaz") que encabeça uma subjetiva, em (46) esse papel já não é claro e em (47) comporta-se de forma autônoma como um marcador discursivo. Na primeira ocorrência, "capaz" expressa a dúvida do falante diante da informação dada pelo interlocutor; nas duas últimas, expressa modalidade epistêmica de alta certeza. O que particulariza dados como (46) é a construção fixa "capaz que não", usada quando o falante quer se contrapor à negação de uma asserção feita pelo interlocutor ou responder enfaticamente "claro que sim" a uma pergunta; já em contextos como (47), o marcador significa "não". Contextos como (46) e (47) se caracterizam por apresentar opinião, pergunta, convite, sugestão da parte do interlocutor, permitindo que o falante se posicione com segurança, com base em algum tipo de evidência, dando uma resposta afirmativa ou negativa.

O contexto de "surpresa", por sua vez, desvia-se da linha central da modalidade. Atentemos para o dado a seguir em comparação a (45).

(48) E: Mãe, sabia que todos os quatro amigos do meu marido tiveram filhos, todos meninos.

N: Capaz! Que legal! Parece que sempre nascem mais meninas, mas neste caso foi o contrário. [dado já apresentado como (31)]

Os contextos (45) e (48) evidenciam um gradiente: dúvida/surpresa > surpresa. Em dados como (45), o falante esboça um movimento de contraposição, mas não tem evidências para sustentar uma posição contrária à do interlocutor, então aceita o que é afirmado pelo outro. A ocorrência (48) e similares parece já ter perdido o componente de dúvida que se percebe em outros contextos, restando ao "capaz" somente a função de expressar surpresa, podendo sobrepor também outros valores como alegria, ironia, etc. Em ambos os casos, trata-se de uma reação diante de uma notícia inesperada, de um fato novo apresentado pelo interlocutor.

No que se refere ao continuum de mudança apresentado para o item "capaz", é interessante observar que trajetória semelhante foi postulada para os adjetivos "lógico" e "claro" (FORTILLI, 2013) e para verbos como "parecer" e "achar" (GONÇALVES, 2003), também envolvendo o uso desses adjetivos e verbos em 
orações matrizes de substantivas encaixadas. As propostas de análise desses autores fortalecem a hipótese de trajetória sugerida para "capaz", na medida em que evidenciam um processo mais geral da língua portuguesa.

Fortilli (2013) analisa construções com predicados adjetivais nos quais se encaixam orações como "(É) lógico que eu vou" e "(É) claro que eu vou", hipotetizando que aquelas iniciadas pelo adjetivo tenham se originado de estruturas complexas constituídas por matriz com a configuração "ser" + adjetivo seguida de orações subjetivas. A autora considera aspectos sintáticos (como uma possível redução da cópula) e semântico-pragmáticos (envolvendo valores modais do adjetivo como de avaliação deôntica e epistêmica) no processo de mudança dessas construções. Gonçalves (2003) analisa a mudança de estatuto categorial de "parecer" (que deixa de ser empregado em funções referenciais da linguagem para expressar atitudes subjetivas do falante) associada a mudanças semântico-pragmáticas que envolvem a emergência de modalidade epistêmica e evidencialidade. O autor postula os seguintes padrões de uso sincrônico, ancorados na evolução diacrônica de "parecer": v. pleno $\left(\right.$ parecer $\left._{1}\right)>$ v. suporte de predicação $\left(\right.$ parecer $\left._{2}\right)>$ v. encaixador de proposição $\left(\right.$ parecer $\left._{3}\right)>$ satélite atitudinal de caráter adverbial $\left(\right.$ parecer $\left._{4,5}\right) \cdot{ }^{18}$

A análise aqui realizada oferece indícios de que "capaz", impulsionado por certos contextos pragmáticos e morfossintáticos, se encontra em processo de mudança, desenvolvendo novas funções gramaticais no âmbito da modalidade epistêmica. À luz dos parâmetros de gramaticalização postulados por Heine e Kuteva (2007), o item se encontra em processo de expansão gradativa que envolve extensão, dessemantização e decategorização, conforme apontado mais acima. Sugerimos, pois, que os usos de "capaz" examinados neste trabalho podem ser interpretados como instâncias de gramaticalização, nos termos da proposta de Rost Snichelotto e Görski (2011) para os marcadores discursivos "olha" e "vê".

\section{CONSIDERAÇÕES FINAIS}

Neste artigo, a partir de uma abordagem baseada no uso, analisamos a multifuncionalidade do item "capaz" na fala gaúcha espontânea, identificando o desenvolvimento de quatro valores no âmbito da modalidade epistêmica (possibilidade, probabilidade, dúvida e certeza), derivados de um significado-

18 As ocorrências a seguir ilustram os cinco tipos de contextos analisados (GONÇALVES, 2003, p. 209):

Parecer: Você parece um pouco aquela menina-como é? ... a Glória Pires (PEUL/CEN/E18)

Parecer $_{2}$ E quanto mais liia [...], tanto me parecia melhor e mais rituoso [...] (15LO, p. 01)

Parecer $_{3}$ [...] Parece que ele estava bêbado, não estava? (PEUL/CEN/E36)

Parecer $_{4}$ : Agora esse fez uma viagenzinha... ele foi parece-me que a Campos do Jordão (NURC/RJ/SET/071)

Parecer $_{5}$ Ela se mudou ontem, parece, eu acho, né Cristina (PEUL/CEN/E50) 
fonte (habilidade) associado à modalidade orientada para o agente. Vimos também que a atitude do falante vai se deslocando do eixo epistêmico da crença, a partir do significado de dúvida, para outras expressões de subjetividade como surpresa, ironia, alegria, etc., diante de um fato irrefutável. Com base no levantamento da frequência de ocorrência de cada tipo de contexto, foi possível delinear padrões de uso do item na amostra analisada: "capaz" é mais recorrente em contextos de certeza (em respostas negativas e afirmativas) e de dúvida/surpresa, aparecendo predominantemente como item sintaticamente autônomo, na função de marcador discursivo. Esses usos foram interpretados como instâncias de gramaticalização.

Mostramos que o funcionamento do item se dá em contexto dialogal de pares adjacentes e que a natureza da informação dada pelo interlocutor (pergunta, opinião, fato/notícia), bem como aspectos prosódicos que envolvem o item são determinantes para a interpretação do significado de "capaz". Nesse sentido, sugerimos como desdobramento deste trabalho a ampliação da amostra para checagem dos padrões identificados nesta análise, bem como a identificação mais precisa da curva entoacional do item em diferentes contextos.

BASSI, A.; GÖRSKI, E. M. The Multifunctionality of the Item 'Capaz' in Gaucho Speech: a UsageBased Approach. Alfa, São Paulo, v.58, n.3, p.593-622, 2014.

- ABSTRACT: Based on a functional approach of language that seeks to identify patterns of use that are originated and established in communicative practices, the present study investigates the multifunctionality of the linguistic item capaz, in a current synchronic sample of gaucho informants, capturing a trajectory of semantic-pragmatic change (associated with values of modality) and categorial change (adjective > discourse marker), which can be interpreted as an instance of grammaticalization. We identified, in the analysis of dialogual contexts: i) values within the epistemic modality (possibility, probability, doubt and certainty), derived from a source meaning (ability) associated with agent-oriented modality, and ii) other expressions of subjectivity as surprise, irony and joy. The control of frequency enabled us to sketch patterns of the use of capaz: the item is more recurrent in contexts of certainty (in affirmative and negative responses) and doubt/surprise, appearing predominantly as a syntactically autonomous item with a function of discourse marker. The nature of the information given by the interlocutor (question, opinion, fact/news) as well as the prosodic aspects that involve the item are decisive for the interpretation of the meaning of capaz.

- KEYWORDS: Capaz. Discourse marker. Dialogual contexts. Modality. Patterns of use.

\section{REFERÊNCIAS}

BOERSMA, P.; WEENINK, D. Praat: doing phonetics by computer. Version 5.1.05. 2009. [Computer program]. Disponível em: <http://www.praat.org/>. Acesso em: 15 abr. 2013. 
BUSARELLO, R. Dicionário básico latino-português. 6.ed. Florianópolis: UFSC, 2005.

BYBEE, J. Language, usage and cognition. Cambridge: Cambridge University Press, 2010.

. From usage to grammar: the mind's response to repetition. Language, Baltimore, v.82, n. 04, p. 711-733, 2006.

BYBEE, J.; PERKINS, R.; PAGLIUCA, W. The evolution of grammar: tense, aspect, and modality in the language of the world. Chicago: The University of Chicago Press, 1994.

COATES, J. The expression of root and epistemic possibility in English. In: BYBEE, J.; FLEISCHMAN, S. (Ed.). Modality in grammar and discourse. Amsterdam/ Philadelphia: John Benjamins Publishing Company, 1995. p.55- 66.

DETGES, U.;WALTEREIT, R. Turn-taking as a trigger for language change. Presentation at the panel on Diachronic Micropragmatics of the Romance Languages, Ninth International Pragmatics Conference (IPra), Toronto, 2003.

FERREIRA, A. B. de H. Novo dicionário Aurélio da língua portuguesa. 2. ed. Rio de Janeiro: Nova Fronteira, 1986.

FORTILLI, S. de C. Orações completivas em posição de sujeito: gramaticalização e dessentencialização de orações matrizes. 2013. 163 f. Tese (Doutorado em Estudos Linguísticos) - Instituto de Biociências, Letras e Ciências Exatas, Universidade Estadual Paulista, São José do Rio Preto, 2013.

GIVÓN, T. Bio-linguistics: the Santa Barbara lectures. Amsterdam: John Benjamins, 2002.

.Tense, aspect and modality I.: functional organization. In: Syntax: an introduction. Amsterdam: John Benjamins, 2001. v. 1, p. 285-335.

Functionalism and grammar. Amsterdam: John Benjamins, 1995.

On understanding grammar. New York: Academic Press, 1979.

GONÇALVES, S. C. L. Gramaticalização, modalidade epistêmica e evidencialidade: um estudo de caso no português do Brasil. 2003. 250 f. Tese (Doutorado em Linguística) - Instituto de Estudos da Linguagem, Universidade Estadual de Campinas, Campinas, 2003.

GUARANY, N. Destino de Peão. In: Destino missioneiro. [S.1.]: Phonogram/Sinter, 1973. 1 disco sonoro. Lado B, faixa 01.

HEINE, B.; CLAUDI, U.; HÜNNEMEYER, F. Grammaticalization: a conceptual framework. Chicago: University of Chicago Press, 1991. 
HEINE, B.; KUTEVA, T. The genesis of grammar: a reconstruction. New York: Oxford University Press, 2007.

HOPPER, P. J. Emergent grammar. BLS, v. 13, p. 139-157, 1987.

HOPPER, P. J.; TRAUGOTT, E. Grammaticalization. Cambridge: Cambridge University Press, 2003.

HOUAISS, A.; VILLAR, M. de S. Dicionário Houaiss da língua portuguesa. 2. ed. Rio de Janeiro: Círculo de Leitores, 2002.

MEILLET, A. L' évolution des formes grammaticales. In: Linguistique historique et linguistique générale. Paris: Champion, 1965. p. 130-148.

RISSO, M. S.; SILVA, G. M.O.; URBANO, H. Marcadores discursivos basicamente seqüenciadores. In: JUBRAN, C. C. A. S.; KOCH, I. G. V. (Org.). Gramática do português culto falado no Brasil. Campinas: Ed. da UNICAMP, 2006. p. 427496. (Construção do texto falado, v. 1).

. Marcadores discursivos: traços definidores. In: KOCH, I. (Org.). Gramática do português falado. Campinas: Ed. da UNICAMP, 1996. v. VI, p. 21-59.

RISSO, M. S.; SILVA, G. M. O.; URBANO, H. Marcadores discursivos basicamente seqüenciadores. In: JUBRAN, C. C. A. S.; KOCH, I. G. V. (Org.). Gramática do português culto falado no Brasil. Campinas: Ed. da UNICAMP, 2006. p. 427496. (Construção do texto falado, v. 1).

ROCHA, P. G. da. As múltiplas funções do item capaz na língua falada pelos gaúchos. Florianópolis, [2008]. Não publicado.

ROST SNICHELOTTO, C. A; GÖRSKI, E. (Inter)subjetivização de marcadores discursivos de base verbal: instâncias de gramaticalização. Alfa, São Paulo, v. 55, n. 2, p. 423-455, 2011.

SCHIFFRIN, D. Discourse markers: language, meaning, and context. In: SCHIFFRIN, D.; TANNEN, D.; HAMILTON, H. The handbook of discourse analysis. Berlin: Blackwell Publishing, 2001. p. 54-75.

Discourse markers. Cambridge: Cambridge University Press, 1987.

TRAUGOTT, E. C. Grammaticalization, constructions and the incremental development of language: suggestions from the development of degree modifiers in English. In:ECKARDT, R.; JÄGER G.; VEENSTRA,T. (Ed.). Variation, selection, development: probing the evolutionary model of language change. Berlin: Mouton de Gruyter, 2008. p. 219-250.

Constructions in grammaticalization. In: JOSEPH, B. D.; JANDA, J. (Ed.).

The handbook of historical linguistic. Oxford: Blackwell, 2003. p. 624-647. 
. From etymology to historical pragmatics. In: MINKOVA, D.; STOCKWELL, R. (Ed.). Studying the history of the english language: millennial perspectives. Berlin: Mouton de Gruyter, 2002. p. 19-49.

. The role of the development of discourse markers in a theory of grammaticalization. In: INTERNATIONAL CONFERENCE ON HISTORICAL LINGUISTICS, 12., 1995, Manchester. Proceedings... Manchester: [s.n.], 1995. Disponível em: <http://www.stanford.edu/ traugott/papers/discourse.pdf>. Acesso em: 20 fev. 2004.

TRAUGOTT, E. C.; DASHER, R. B. The development of modal verbs. In:TRAUGOTT, E. C.; DASHER, R. B. Regularity in semantic change. Cambridge: Cambridge U.P., 2005. p.105-151.

TRAUGOTT, E. C.; HEINE, B. (Ed.). Approaches to grammaticalization. Philadelphia: John Benjamins Company, 1991. v. 1-2.

TRAUGOTT, E. C.; KÖNIG, E. The semantics-pragmatics of grammaticalization revisited. In: TRAUGOTT, E. C.; HEINE, B. (Ed.). Approaches to grammaticalization. Philadelphia: John Benjamins Company, 1991. v. 1-2, p. 189-218.

URBANO, H. Marcadores conversacionais. In: PRETI, D. (Org.). Análise de textos orais. 3.ed. São Paulo: Humanitas, 1997. v. I, p. 81-101.

WALTEREIT, R. The rise of discourse markers in Italian: a specific type of language change. In: FISCHER, K. (Ed.). Approaches to discourse markers. Oxford: Elsevier, 2006. p.61-76.

Recebido em maio de 2013.

Aprovado em agosto de 2013. 